\title{
Preterm vaginal en caul delivery in a case of severe oligohydramnios with pyelonephritis
}

\author{
Kashmira Ghosh*, Arun Paul Choudhury
}

Department of Obstetrics and Gynecology, Silchar Medical College, Silchar, Assam, India

Received: 07 October 2020

Accepted: 12 November 2020

\section{*Correspondence:}

Dr. Kashmira Ghosh,

E-mail: krishkash.ghosh@gmal.com

Copyright: (c) the author(s), publisher and licensee Medip Academy. This is an open-access article distributed under the terms of the Creative Commons Attribution Non-Commercial License, which permits unrestricted non-commercial use, distribution, and reproduction in any medium, provided the original work is properly cited.

\begin{abstract}
En caul deliveries are very rare and are associated with prematurity. Approximately 40 percent of spontaneous premature births are thought to be caused by infection. Preterm along with oligohydramnios can lead to en caul delivery. We report a case of 27-year-old gravida 4 multiparous women with a history of 2 normal vaginal deliveries NSVD and 1 spontaneous abortion, who presented at 32 weeks of gestation in active labour and delivered preterm viable female with an intact placenta contained within the amniotic sac as a unit "en caul." Since the patient gave a history of lower back pain with burning micturition for 1 month which remained consistent after delivery, ultrasonography whole abdomen was done and bilateral pyelonephritis was diagnosed. However, the baby's sepsis screen was negative and discharged healthy. We report this case because of its rarity of occurrence and to show that intact amniotic membrane during birth can protect the baby from birth trauma and infections.
\end{abstract}

Keywords: En caul, Preterm, Oligohydramnios, Pyelonephritis

\section{INTRODUCTION}

During pregnancy, the fetus is enclosed in an amniotic sac filled with amniotic fluid. "Amnion" also called "caul" (in French) is a tough and tenacious but pliable membrane. In a normal full-term delivery, the amniotic sac ruptures spontaneously and the fetus is delivered through the vaginal opening followed by delivery of the placenta. A "caul" delivery occurs when a piece of the amniotic sac is still attached to the neonate at the time of delivery, usually attached to the head or torso. ${ }^{1,2}$ When the entire intact amnion is delivered with the Fetus inside, it is called an en caul delivery. Of all vaginal deliveries, roughly 1 in 80,000, membranes do not rupture. ${ }^{2,3}$ Most en caul births are associated with prematurity. The nervous system of preterm infants is incompletely developed, and their tolerance to hypoxia and mechanical stimulation is low. When the infant is delivered en caul, it is protected by the surrounding amniotic fluid within the intact fetal membranes up to the last moment.
Approximately 40 percent of spontaneous premature births are thought to be caused by infection. ${ }^{7}$ One mechanism by which microorganisms might cause preterm labor is through ascension from the cervical/vaginal area and replication in the placenta, decidua and membranes. ${ }^{8}$ Inflammatory responses drive the pathogenesis of infection-induced preterm labor. Lipopolysaccharide (LPS) or other toxins elaborated by bacteria are recognized by pattern-recognition receptors such as toll like receptors. These receptors are present on mononuclear phagocytes, decidual cells, cervical epithelia, and trophoblasts activation of toll-like receptors induces a signaling cascade that activates production of chemokines such as interleukin 8 (IL-8) and cytokines such as IL-1 $\beta$. In many tissues, including myometrium, decidua, and amnion, IL-1 $\beta$ promotes prostaglandin formation that induces cervical ripening and loss of myometrial quiescence. ${ }^{9}$ 


\section{CASE REPORT}

We report a case of a 27-year-old gravida 4 multiparous woman with a history of 2 normal vaginal deliveries (NSVD and 1 spontaneous abortion, presented at 32 weeks gestation by dates. The patient presented with severe abdominal pain with contractions and strong bearing down. She denied vaginal bleeding, spontaneous rupture of membranes, or fetal movements. Her vitals were within normal limits. The cervical ostium was fully dilated and was $100 \%$ effaced with crowning of head; membranes were intact and adherent to the presenting part. The patient was admitted to the labor room and she continued to bear down. Antenatal steroid therapy was not administered as she was already in active labour. She was given antibiotics prophylactically and intravenous fluids. The patient delivered a preterm viable female with an intact placenta contained within the amniotic sac as a unit "en caul." The membranes were adherent to the body of the newborn and there was minimal liquor inside the sac. The amniotic sac was immediately torn, and a female newborn was extracted. The minimal liquor was clear and no abnormalities were detected. The delivery of the infant with placenta took 15 minutes. The newborn was emergently assessed, and managed by a neonatologist. The baby did not cry soon after birth. She was intubated with bag and tube ventilation for 2 minutes. The baby started breathing spontaneously and was extubated. The newborn's weight was $2.1 \mathrm{~kg}$, Apgar scores were 4, 6, and 8 at 1, 5, and 10 minutes, respectively and her gestational age was calculated to be 34-36 weeks as per the new Ballard scoring system. No lacerations or tears were noted in the vaginal canal, and the fundus of the uterus was firm. The female newborn had CRT >3 seconds and oxygen saturation were $93 \%$. She was put on CPAP, given a stress dose of hydrocortisone and put on dopamine drip for hypotension. Her sepsis screen was negative. She started to recover from day 2 and was started with breastfeeding and was shifted with mother on day 4. The patient however gave a history of lower back pain with burning micturition for 1 month. After delivery, her lower backpain remained consistent. Ultrasonography whole abdomen was done and bilateral pyelonephritis was diagnosed. She was later shifted to medicine unit for further management.

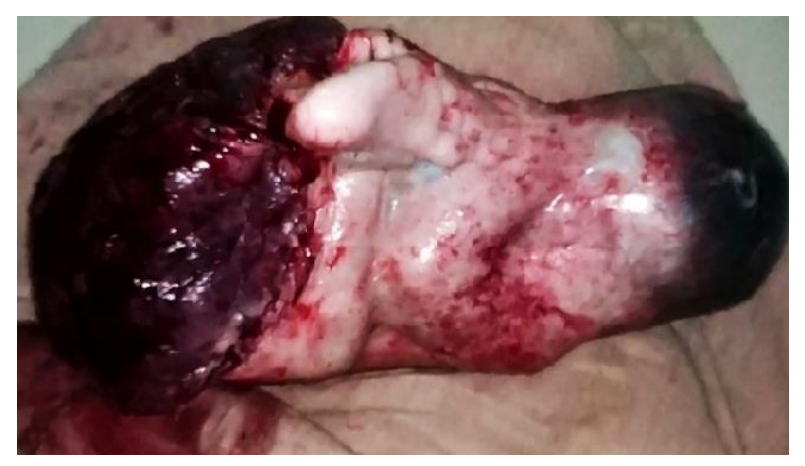

Figure 1: Baby born en caul, membrane adherent to the body of the baby due to severe oligohydramnios.

\section{DISCUSSION}

En caul deliveries are extremely rare. The majority of en caul deliveries occur in premature neonates. ${ }^{2-4}$ The caul is harmless and intact amniotic membranes provide a protective buffer from mechanical forces, such as potential bruising injuries and other examples of labor and delivery trauma during strong uterine contractions. ${ }^{10}$ Other benefits include the opportunity to complete a course of steroids, high cord pH, higher 5-minute Apgar scores for extremely preterm infants, protection from cord prolapse, and decreased risk of entrapment of the head in the setting of an insufficiently dilated cervix. ${ }^{4-7}$

The first fetus born in a complete caul was reported in 1975. The infant survived 25 minutes of extrauterine life inside the intact sac of membrane and no ill effects were demonstrated after a follow-up of 3 years. ${ }^{14}$ A case describes a 23-week infant born via cesarean section who lived without complications. ${ }^{15}$ Another case report describes a birth at 22 weeks and 6 days to a nulliparous woman; the infant died at 23 hours due to intraventricular hemorrhage and sepsis. ${ }^{5}$ A fourth case outlines a birth at 23 weeks and 2 days to a $1+2$ para woman; the infant died at 19 hours due to pulmonary hemorrhage. ${ }^{5}$ There is also mention of a birth at 23 weeks and 5 days to a $0+2$ para woman; the infant was discharged at 104 days of life with no further information available regarding her health.

Respiratory distress, sepsis, and hemorrhagic complications may occur in postpartum period after en caul birth. From the mentioned cases, however, opinion can be drawn that the preterm complications of en caul are similar to those of preterm non en caul. It has been seen that born en caul is beneficial for preterm babies, however the cause is still not well understood. Though maternal infection may cause preterm birth, in our case it has been seen that the baby did not suffer from sepsis even though mother had history of urinary tract infection.

Tension on the membranes plays an important role in the success of en caul delivery. The fetal membranes are composed of connective tissue with collagen and elastic fibrils. Both confer strength and elasticity, which maintains tissue tension. The fetal membranes stop growing in the second trimester but are able to adapt to the expanding uterus in late pregnancy because of these elastic properties. ${ }^{11}$ As gestation progresses, the types of collagen and the structures of the fetal membranes change, and the membranes become increasingly thin near the area of rupture. ${ }^{12,13}$ Conditions such as oligohydramnios and lower birthweights, the volume of the uterine cavity is less while at the same time the membrane tension becomes less providing more potential for the fetal membrane sac to not rupture easily. Oligohydramnios has not been previously proposed as a cause of en caul delivery. We therefore report this case of en caul delivery with severe oligohydramnios. 
This case is a rare case in our institution. We advise immediate Neonatologist consultation, respiratory intervention, aggressive preterm management, and neonatal intensive care unit (NICU) services for such babies. Pulmonary hypoplasia can result from severe oligohydramnios of as short as 6 days duration and respiratory distress syndrome should be ruled out. ${ }^{16}$

\section{CONCLUSION}

En caul delivery is a rare phenomenon. Maternal infection can induce preterm labour. Preterm delivery along with oligohydramnios can lead to en caul birth. However, the intact membrane proves to be a protective sac to protect the baby from birth trauma and infection.

Funding: No funding sources Conflict of interest: None declared Ethical approval: Not required

\section{REFERENCES}

1. Lin CH, Lin SY, Yang YH, Shih JC, Shih JC, Lee $\mathrm{CN}$ et al. Extremely Preterm Cesarean Delivery "En Caul. Taiwanese J Obstet Gynecol. 2010;49(3):2549.

2. Greenstein J, Panzo W, O’Connor J, Hahn B. En Caul delivery. J Emergency Med. 2016;50(2):333-4.

3. Abouzeid H, Tornton JG. Pre-term delivery by Caesarean section 'en caul': A case series. Eur J Obst Gynecol Reprod Biol. 1999;84(1)51-3.

4. Jin, ZX, Wang Q, Xu P, Wang, Ai W. Cesarean section en caul and asphyxia in preterm infants. Acta Obstetricia et Gynecologica Scandinavica. 2013;92(3):338-41

5. Richmond JR, Morin L, Benjamin A. Extremely Preterm Vaginal Breech Delivery en Caul. Obste Gynecol. 2002;99(6):1025-0.

6. Stoelinga B, Bienstock J, Goodwin C, Hueppchen N. En caul delivery of extremely preterm infants: Does it make a difference? Am J Obste Gynecol. 2006;195(6):S75.
7. Lettieri L, Vintzileos AM, Rodis JF, Albini SM, Salafia CM. Does idiopathic preterm labor resulting in preterm birth exist? Am J Obstet Gynecol. 1993;168:1480-5.

8. Minkoff H. Prematurity: infection as an etiologic factor. Obstet Gynecol. 1983;62:137-44.

9. Cunningham FG, Leveno KJ, Bloom SL, Dashe JS, Hoffman BL, Casey BM, Spong CY, Preterm birth. In:Williams obstetrics. $25^{\text {th }}$ ed. New York. McGrawHill Edu. 2018:811-2.

10. Malik R, Sarfraz A, Faroqui R, Onyebeke W, Wanerman J. Extremely Preterm (23 Weeks) Vaginal Cephalic Delivery En Caul and Subsequent Postpartum Intraventricular Hemorrhage and Respiratory Distress: A Teaching Case. Hindawi Case Reports Obst Gynecol. 2018,2018:3.

11. Kelly $\mathrm{T}$. The pathophysiology of premature rupture of the membranes. Curr Opin Obstet Gynecol. 1995;7:140-5.

12. Polzin WJ, Brady K. The etiology of premature rupture of the membranes. Clin Obstet Gynecol. 1998;41:810-6.

13. Taylor KH, Schnabel RD, Taylor JF. Impaired collagen chaperone results in preterm PROM. Proc Natl Acad Sci USA. 2006;103:13267-8.

14. Heggarty H, Shenouda D, Grisdale M. Born in a caul. Remarkable survival. Am J Dis Child. 1975;129:955.

15. Prabakar C, Nimaroff ML. Perfectly packaged: Upon delivery, the infant was still enclosed in the amniotic sac. Am J Obste Gynecol. 2012;207(1):80-1.

16. Thibeault DW, Eugene C, Beatty Jr, Robert T, Hall MT, Sandra K et al. Neonatal pulmonary hypoplasia with premature rupture of fetal membranes and oligohydramnios. J Pediat. 1985;107:2:273-7.

Cite this article as: Ghosh K, Choudhury AP. Preterm vaginal en caul delivery in a case of severe oligohydramnios with pyelonephritis. Int J Reprod Contracept Obstet Gynecol 2020;9:5197-9. 